\title{
MANAGEMENT OF ENDOCRINE DISEASE Outcome of adrenal sparing surgery in heritable pheochromocytoma
}

\author{
F Castinetti ${ }^{1}$, D Taieb ${ }^{2}$, J F Henry ${ }^{3}$, M Walz ${ }^{4}$, C Guerin ${ }^{3}$, T Brue ${ }^{1}$, B Conte-Devolx ${ }^{1}$, \\ H P H Neumann ${ }^{5}$ and F Sebag ${ }^{3}$
}

${ }^{1}$ Department of Endocrinology, La Conception Hospital, ${ }^{2}$ Department of Nuclear Medicine, La Timone Hospital and ${ }^{3}$ Department of Endocrine Surgery, La Conception Hospital, Assistance Publique Hopitaux de Marseille, Aix-Marseille University, Marseille, France, ${ }^{4}$ Department of Surgery, Center of Minimally Invasive Surgery, Kliniken Essen-Mitte, Essen, Germany and ${ }^{5}$ Section for Preventive Medicine, Department of Nephrology and General Medicine, University Medical Centre, Albert Ludwigs University of Freiburg, Freiburg, Germany
Correspondence should be addressed to F Castinetti Email Frederic.castinetti@ap-hm.fr

\begin{abstract}
The management of hereditary pheochromocytoma has drastically evolved in the last 20 years. Bilateral pheochromocytoma does not increase mortality in MEN2 or von Hippel-Lindau ( $V H L)$ mutation carriers who are followed regularly, but these mutations induce major morbidities if total bilateral adrenalectomy is performed. Cortical sparing adrenal surgery may be proposed to avoid definitive adrenal insufficiency. The surgical goal is to leave sufficient cortical tissue to avoid glucocorticoid replacement therapy. This approach was achieved by the progressive experience of minimally invasive surgery via the transperitoneal or retroperitoneal route. Cortical sparing adrenal surgery exhibits $<5 \%$ significant recurrence after 10 years of follow-up and normal glucocorticoid function in more than $50 \%$ of the cases. Therefore, cortical sparing adrenal surgery should be systematically considered in the management of all patients with MEN2 or VHL hereditary pheochromocytoma. Hereditary pheochromocytoma is a rare disease, and a randomized trial comparing cortical sparing vs classical adrenalectomy is probably not possible. This lack of data most likely explains why cortical sparing surgery has not been adopted in most expert centers that perform at least 20 procedures per year for the treatment of this disease. This review examined recent data to provide insight into the technique, its indications, and the results and subsequent follow-up in the management of patients with hereditary pheochromocytoma with a special emphasis on MEN2.
\end{abstract}

\section{Introduction}

Pheochromocytoma is a rare neuroendocrine tumor (estimated annual incidence of 2-8 per million) that arises from chromaffin cells in the adrenal medulla $(1,2)$. It is considered a sporadic disease in most cases (3). The contribution of heredity increased to $25 \%$ with the discovery of new susceptibility genes, such as succinate

\section{Invited Author's profile}

Frederic Castinetti, MD, PhD, is an Associate Professor of Endocrinology at Aix-Marseille University, France. Dr Castinetti is currently working on new etiologies of congenital hypopituitarism. His primary clinical interests are pituitary disorders, including optimal management of pituitary deficiencies, pituitary adenoma diagnosis and management, and adrenal disorders. Dr Castinetti is particularly interested in the management of hypercortisolism, the early diagnosis of the recurrence of Cushing's disease, and the long-term consequences of high glucocorticoid exposure. Finally, Dr Castinetti's recent work focused on the management of hereditary pheochromocytoma.

(C) 2016 European Society of Endocrinology Printed in Great Britain
Published by Bioscientifica Ltd.

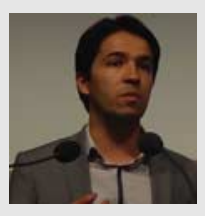


dehydrogenase $(S D H), M A X$ or TMEM127 $(4,5,6)$. Overall, $S D H B, S D H D, R E T, V H L$, and NF1 germinal mutations represent most of the genetic etiologies of pheochromocytoma and paraganglioma (6). SDHB and SDHD mutations primarily lead to unilateral pheochromocytoma and whole-body paraganglioma, with up to $40 \%$ malignity for SDHB mutations (7). In contrast, bilateral pheochromocytoma is observed in syndromic diseases due to mutations of RET, which leads to MEN2, von HippelLindau (VHL) syndrome or neurofibromatosis type 1 (NF1) (3). MEN2 is an autosomal dominant disease in which medullary thyroid carcinoma (MTC) is present in 100\% of the cases, and pheochromocytoma occurs in $\sim 50 \%$ of MTC cases either concurrently or after the diagnosis of MTC (8). VHL is an autosomal dominant syndrome that primarily includes the central nervous system or retinal capillary hemangioblastoma, and pheochromocytoma occurs in $\sim 20 \%$ of VHL cases (specifically in type 2) (9). The mean age at first diagnosis of pheochromocytoma (unilateral or synchronous bilateral) is $\sim 30-40$ years in both genetic etiologies, and the risk of malignancy is low $(<5 \%)(8)$. The management and follow-up of MTC in MEN2-mutation carriers is well codified as early thyroidectomy (10), which suggests that pheochromocytoma has progressively become the main determinant of the outcome in these patients.

However, the impact of pheochromocytoma in MEN2mutation carrier mortality in the 21st century is lower than expected. Only two deaths presumably due to pheochromocytoma were reported in 107 patients with the frequent germline 634-RET codon mutation (11), and these deaths were observed during surgery in the 1960s. We reported a similar result in a large international study of only deaths out of 563 patients with MEN2-associated pheochromocytoma (12). The results are similar for $V H L$ mutation carriers (9). Bilateral pheochromocytoma exhibits a major functional impact following total bilateral adrenalectomy, which is still used in many centers. Approximately $50 \%$ of MEN2 and $20 \%$ of VHL patients present bilateral pheochromocytoma by age 50 , and these patients become adrenal insufficient following bilateral adrenalectomy $(12,13,14)$. The commonly encountered adverse side effects with chronic steroid dependence are well defined, and insufficient steroid replacement may lead to Addisonian crisis and death. Excessive steroid replacement is associated with premature osteoporosis, hypertension, and diabetes. Chronic steroid side effects also include an altered quality of life (15). Notably, even patients who receive appropriate information on the management of their chronic adrenal insufficiency are at risk of Addisonian crisis, which is a life-threatening emergency that may occur when the replacement dosage is not increased by the patient despite a major stress. A large, recent study of 423 educated patients reported a risk of 8.3 Addisonian crises per 100 patient-years and the occurrence of 0.5 Addisonian crisis-related deaths per 100 patient-years $(16,17)$. Changing the functional prognosis of MEN2 or VHL mutation carriers will require modifications in the treatment of patients with bilateral pheochromocytoma.

Surgical teams adopted different techniques to avoid the consequences of adrenal insufficiency in patients with bilateral pheochromocytoma. Adrenal autotransplantation was performed with limited success, and sufficient autograft functioned in $<30 \%$ of the cases (18). Therefore, this technique has been nearly abandoned. Cortical sparing adrenal surgery is increasingly performed. Cortical sparing is a surgical technique in which the surgeon leaves a small amount of vascularized unilateral or bilateral adrenal tissue that will be sufficient to maintain the normal function of the adrenal cortex for a prolonged period of time. This technique was successfully tested in pheochromocytoma and aldosterone-producing adenoma. The present review provides insight on the merits and pitfalls of cortical sparing adrenal surgery in the management of hereditary pheochromocytoma with a special emphasis on MEN2 and VHL mutation carriers.

\section{Diagnosis of hereditary pheochromocytoma}

Pheochromocytoma is detected concurrent with the genetic diagnosis or during the follow-up of mutation carriers who are diagnosed by familial screening. The steps of diagnosis are identical, but the option of cortical sparing adrenal surgery is more obvious in mutation carriers because the pheochromocytoma is generally smaller.

\section{In the propositus (when pheochromocytoma is present at the genetic diagnosis)}

The diagnosis of pheochromocytoma is biochemically based on increased levels of plasma or urinary-free normetanephrines and metanephrines (sensitivity 97-100\%, specificity 100\%) (2). VHL-associated pheochromocytoma usually secretes normetanephrines, and few of these tumors secrete metanephrines (19). The profile of MEN2-associated pheochromocytoma is the co-secretion of both biological markers (19). Conventional imaging is performed using computed tomography (CT) or MRI (with 1-2 mm slice thickness) because both of these techniques 
exhibit high sensitivity and specificity (90-100 and $70-80 \%$ respectively) (2). CT or MRI will allow for the precise determination of the size of the pheochromocytoma, the number of lesions and the possibility of performing a partial adrenalectomy.

The role of metabolic imaging in sporadic pheochromocytoma is debatable, but it is important in hereditary pheochromocytoma. Metabolic imaging aids in the detection of additional smaller secreting lesions in the same or contralateral gland. Limited data are available in the current literature on functional imaging studies in MEN2-associated pheochromocytoma (20). One special advantage of ${ }^{18} \mathrm{~F}$-FDOPA (3,4-dihydroxy-6-(18)F-fluoro1-phenylalanine) PET over metaiodobenzylguanidine (MIBG) stems from its lack of high uptake in normal adrenal glands (21). The recent European Association of Nuclear Medicine (EANM) guidelines state that ${ }^{18} \mathrm{~F}$-FDOPA uptake should be considered pathological only in cases of asymmetrical adrenal uptake with a concordant enlarged gland or adrenal uptake that is more intense than the liver with a concordant enlarged gland (22). We consider that ${ }^{18}$ F-FDOPA should be the optimal metabolic imaging technique if it is performed during the decision process for cortical sparing surgery. The MIBG scan is another option for the evaluation of these tumors. ${ }^{123}$ I-MIBG scintigraphy is preferable to ${ }^{131}$ I-MIBG scintigraphy (23). However, the main drawback of the MIBG scan is related to the high uptake by normal adrenal medulla. ${ }^{18} \mathrm{~F}-\mathrm{FDG}$ PET is suboptimal in the diagnosis of MEN2- and NF1associated pheochromocytoma, but some tumors may exhibit high tracer uptake (20). SDHx- and VHL-associated pheochromocytoma exhibit high avidity for ${ }^{18}$ F-FDG (24).

\section{In mutation carriers (without pheochromocytoma at the time of genetic diagnosis)}

The way to follow mutation carriers is debatable. However, the follow-up is crucial for the option of cortical sparing surgery. Symptoms and signs of catecholamine oversecretion (e.g., palpitations, hypertension, sweating) must be considered, but these symptoms are frequently absent in mutation carriers that show a progressive increase of metanephrines. Therefore, plasma or urinaryfree normetanephrines and metanephrines should be monitored annually. The age to begin screening is well codified for MEN2-associated pheochromocytoma, depending on RET mutation, but VHL-associated pheochromocytoma can occur during early childhood (25). This biological screening should be ideally maintained throughout the patient's lifetime.
Questions remain for the need to perform regular imaging in asymptomatic patients with negative biology. In our large cohort, 75/460 (16\%) at-risk MEN2 patients underwent CT or MIBG scans every 2-5 years despite negative biology (12). The theoretical risk of not being able to perform partial adrenalectomy because of the size of the pheochromocytoma is rather low because a large MEN2- or VHL-associated pheochromocytoma would be secreting and detected using biological testing. However, the performance of regular imaging (with $1 \mathrm{~mm}$ slices) could aid in the detection of a small $(<1 \mathrm{~cm})$ and nonsecreting pheochromocytoma. This screening would help define the intervals of further imaging surveillance or impact the decision for an early surgery, and cortical sparing surgery would be technically available at this stage. Radiation toxicity should also be considered, which supports the use of MRI rather than CT in patients who are willing to undergo imaging surveillance. In summary, whether imaging should play a role during the follow-up of these patients is not known, but it seems obvious that if it is performed, then it should not be performed too frequently. We suggest the performance of adrenal MRI every 3-5 years, and there is likely no place for nuclear imaging in this setting of surveillance.

\section{Technique of cortical sparing surgery}

The performance of classical adrenalectomy or cortical sparing adrenal surgery does not modify the pre-surgical management of patients. The Endocrine Society guidelines recommend the maintenance of normal blood pressure levels using $\alpha$ blockers followed by $\beta$ blockers before surgery (2). We consider that most patients are controlled with calcium blockers, but one major factor in the treatment is the experience of the surgeon and anesthesiologist in the management of pheochromocytoma.

\section{When to perform cortical sparing surgery}

The possibility of cortical sparing surgery is evoked based on three assumptions: i) a very low risk of malignancy; ii) a reasonable risk of recurrence that is easily followed, diagnosed and cured; and iii) a high chance of maintaining normal adrenal cortical function. The use of this technique in unilateral pheochromocytoma is highly debated, which is why the literature data on partial adrenalectomy only focus on patients with RET or VHL mutations $(12,18,26,27,28,29,30,31,32,33,34)$. The low risk of malignancy and high risk of bilateral 
pheochromocytoma are obvious in these genetic cases, especially in MEN2 (12).

The main difficulty in cortical sparing surgery for the risk of recurrence is that it is impossible to ensure that there is no remaining medullar tissue. The predisposing mutation in MEN2 involves all of the medullar cells, with hyperplasia preceding pheochromocytoma (35). The macroscopic difference between the cortex and the medulla is easy to see (Fig. 1), but expert surgeons report that the possibility of having a clear post-surgical cortex without any medullar cells is a myth. The remaining medullar tissue will systematically lead to a recurrence of pheochromocytoma, but not for a prolonged period of time (as described in detail in the next chapter).

Conventional imaging (with $1 \mathrm{~mm}$ slices) will provide clues to determine whether the surgeon can safely maintain any adrenal tissue. The assumption will be based on the maximum size of the pheochromocytoma and the presence of other pheochromocytoma in the gland. A pheochromocytoma larger than $5 \mathrm{~cm}$ could make it difficult to perform partial adrenalectomy because a specific anatomical position of the tumor would be necessary. At least one-quarter to one-third of the gland is needed to maintain normal cortical function $(29,30,34)$. This minimal amount is sometimes impossible to obtain because of the large size of the pheochromocytoma and the presence of several smaller associated pheochromocytoma in the same gland. The decision of the appropriateness of cortical sparing adrenal surgery in these cases depends on the surgeon's experience, which may be aided with intraoperative sonography.

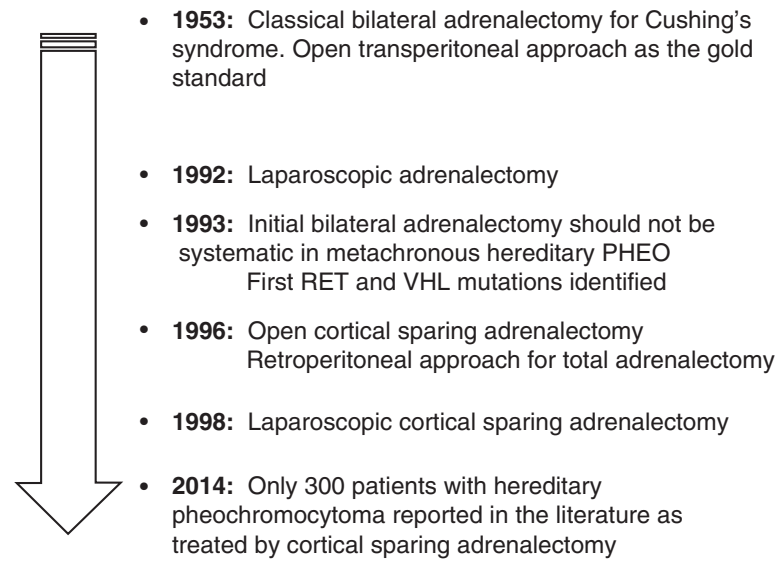

\section{Figure 1}

The history of adrenalectomy and cortical sparing adrenal surgery for hereditary (MEN2 and VHL) pheochromocytoma.

\section{How to perform cortical sparing surgery}

Surgery for pheochromocytoma has progressively evolved in the last 20 years from open to minimally invasive surgery. Surgery of these tumors has always been risky because of the possible delivery of catecholamines during the surgery, even in normotensive patients $(36,37)$. Operative risks were progressively reduced by medical pretreatment, improvement of the techniques and experience acquired in specialized surgical centers $(38,39)$. Preservation of the main adrenal vein is not necessary to gain sufficient cortical function because the gland has many blood supplies (34). Minimally invasive adrenalectomy was first described in 1992 (40), and it is now the standard treatment for benign pheochromocytoma via the transperitoneal or retroperitoneal approach. These procedures have many advantages compared to open adrenalectomy, such as very rare mortality, lower blood loss, better hemodynamic stability, decreased morbidity including decreased post-surgical pain and ileus, shorter hospital stay, better esthetic results, and faster return to daily life activities (41). Questions on minimally invasive surgery remain for malignant or very large tumors, which are not crucial in patients who should benefit from cortical sparing adrenal surgery (42). Minimally invasive surgery is likely the best surgical approach for candidates of partial adrenalectomy because it provides an optimal view and light on the gland, which is deeply located in the abdomen, and it is less traumatic. This surgery makes a second surgery easier even with minimally invasive surgery or the use of another cortical sparing approach in case of recurrence $(43,44)$. Cortical sparing adrenal surgery has been made easier as soon as the endoscopic approach became the gold standard. Our recent study reported a progressive increase in the number of cortical sparing procedures following a progressive increase in the number of endoscopic procedures (33\% vs $8 \%$ and $64 \%$ vs 8\% using both techniques before 1999 and after 2009, respectively) (12).

The transperitoneal approach has the advantage of having a large operative field, which provides a wellknown anatomical view for the surgeon, and it is frequently used for adrenal surgery. However, the adrenals are located in the upper retroperitoneal space, and a retroperitoneal approach for total adrenalectomy was developed 20 years ago (45). A retroperitoneoscopic approach allows direct, rapid access to the adrenal gland without incursion into intra-abdominal viscera and provides a detailed view of the adrenal gland and its surrounding region. This approach is performed in a prone 
position, and it requires dilatation of the retroperitoneum. The primary contraindication to this approach is a largesized tumor $(>8 \mathrm{~cm})$ due to the limited operative field. Severe obesity is another relative contraindication because it also reduces the operative field, and thick fat retroperitoneal tissue makes the surgery more difficult. Opponents to this technique also mention that the small operative field and the inability to explore the abdominal cavity may represent strong limitations to this approach (46). Anesthesiology analyses reported hemodynamic changes, such as significant increases in cardiac output, stroke volume, mean arterial pressure, mean pulmonary arterial pressure, and central venous pressure, without apparent adverse effects (47). The same approach was used for cortical sparing adrenal surgery in 22 patients, including two patients with MEN2 (34). This study was followed by several other studies by different teams, which suggests a better outcome for patients in terms of postoperative pain $(48,49)$. This technique has the advantage of allowing the performance of bilateral adrenalectomy without patient repositioning, which decreases the duration of surgery. A recent study compared transperitoneal $(n=26)$ and retroperitoneal $(n=17)$ approaches for unilateral endoscopic procedures in adrenal tumors. No patient had hereditary pheochromocytoma. Blood loss was similar in both groups, but the mean operative time, the mean time to first oral intake, the global consumption of painkillers, and the mean time of hospital stay were reduced in the retroperitoneal group (46).

In summary, minimally invasive surgery should be the preferred surgical procedure when performing cortical sparing adrenal surgery. The endocrine surgeon should decide the transperitoneal or retroperitoneal route because neither approach is better from a functional viewpoint. The postsurgical comfort of the patient may be improved with the latter approach (50), but the necessity of a learning curve due to an unusual anatomical view could make it more difficult to obtain effective results initially (51). Notably, the low morbidity of cortical sparing adrenal surgery and the similar duration of the intervention do not exhibit evidence in favor of total adrenalectomy from a technical viewpoint (52).

\section{Adrenal function and recurrence after cortical sparing surgery}

The efficacy of cortical sparing adrenal surgery can be evaluated using two parameters: i) the rate of recurrence and ii) the rate of normal adrenal function when adrenal sparing surgery is performed in at least one adrenal in patients with bilateral pheochromocytoma (Fig. 2).

One of the primary issues when trying to determine the outcome of patients treated by this specific surgical approach is the low number of studies in the literature. An exhaustive search in PubMed using the words 'partial adrenalectomy,' 'cortical sparing,' 'adrenal sparing,' or 'adrenalectomy' for the first published report on cortical sparing adrenal surgery revealed 69 original studies/case reports, with only 25 studies that dealt with more than ten patients. Narrowing the search to hereditary pheochromocytoma led to ten studies of at least ten MEN2 or VHL patients. The length of follow-up is also an issue because three ought of ten studies had a follow-up that
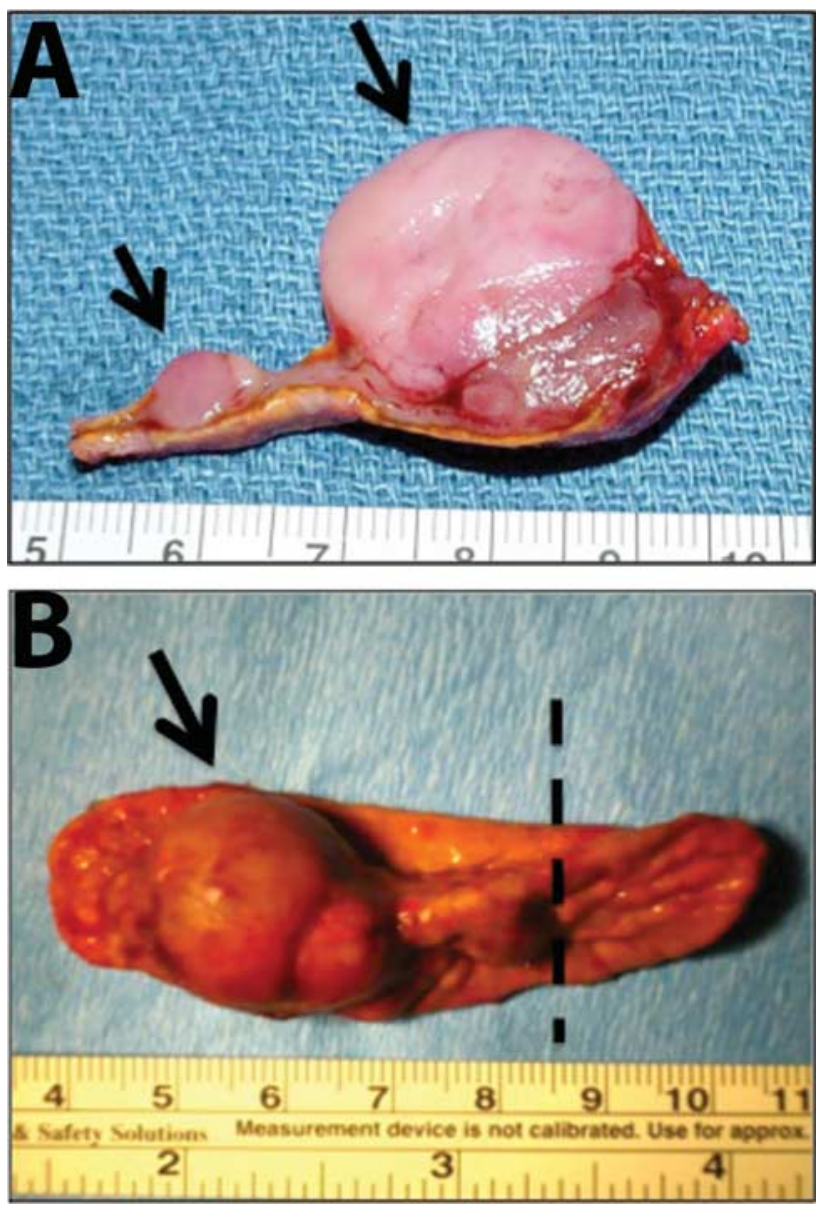

\section{Figure 2}

Operated adrenal glands from MEN2 patients. (A) Two pheochromocytomas in the same gland (depicted by arrows), which impedes adrenal sparing surgery. Note the cortex in yellow and the medulla in pink. (B) Single pheochromocytoma that could have led to successful adrenal sparing surgery. 
was $<5$ years, which likely underevaluates the risk of significant recurrence in patients treated with this type of approach. Precise definitions of the recurrence (e.g., symptomatic, biological, or identified by imaging) was not always clearly mentioned. Table 1 summarizes these studies $(12,26,27,28,29,30,31,32,33,53)$.

The overall risk of recurrence in pheochromocytoma following cortical sparing adrenal surgery is estimated as $0-21 \%$. One study reported an estimated risk of recurrence $>50 \%$, but the number of patients having a follow-up $>5$ years was low, and the risk was extrapolated (27). The risk of recurrence seems lower in most recent studies, which primarily used endoscopic approaches, and risk is higher in older studies, which were based only on open adrenalectomy as shown in Table 1 . These results confirm that endoscopy induced better functional results because of the magnification that is achieved using endoscopic equipment (54). Notably, the risk is not necessarily higher in studies with a longer follow-up. However, these studies rarely report follow-ups of more than 10 years, which is likely not sufficient. We recently reported the largest investigation of cortical sparing adrenal surgery in 114 MEN2 patients. Notably, our study was based on 533 patients operated for MEN2-associated pheochromocytoma, and it did not find any significant difference in the rate of recurrence between patients treated by total or partial adrenalectomy. In the cortical sparing group, four of $153(2.6 \%)$ operated glands presented recurrence after a mean follow-up of 10 years, and 11 of 717 (1.5\%) presented recurrence after a mean follow-up of 13 years in the adrenalectomy group. The mean time to recurrence in the entire cohort was 9.5 years, but two patients with cortical sparing adrenal surgery presented recurrence 11 and 13 years after surgery, which clearly indicates that a longer follow-up is required to develop a better idea of long-term recurrence risk (12). This longer follow-up is also needed for classical adrenalectomy because the risk of recurrence after total laparoscopic adrenalectomy for pheochromocytoma is very low, but the follow-up is generally $<5$ years $(55,56)$.

Glucocorticoid function was normal in $57-100 \%$ of patients treated for bilateral pheochromocytoma with at least one adrenal sparing surgery. The diagnosis of adrenal insufficiency was based on a low $0800 \mathrm{~h}$ cortisol level and an insufficient cortisol response to an adrenocorticotropic hormone (ACTH) test. Two studies reported normal $0800 \mathrm{~h}$ plasma cortisol levels but subnormal cortisol response to the ACTH test, and these patients did not require glucocorticoid substitution $(29,33)$. No occurrence of Addisonian crisis was reported during the follow-up in

Table 1 Literature search on cortical-sparing adrenal surgery. Studies were selected if at least ten patients were treated in the indication of hereditary pheochromocytoma. The criteria used to define normal adrenal function were normal cortisol response (between 18 and $20 \mu \mathrm{g} / \mathrm{dl}$ 30-60 min after cosyntropin stimulation test) for all studies except for Benhammou et al. (28) (need for corticosteroid replacement) and Alesina 2012 (26) (Follow-up data were obtained by contacting the general physician or the referral endocrinologist.) Recurrence was defined as biochemical and/or radiological evidence of pheochromocytoma.

\begin{tabular}{|c|c|c|c|c|c|c|}
\hline References & Patients & Genetics & Surgical approach & Recurrence & $\begin{array}{l}\text { Normal glucocorticoid } \\
\text { function }\end{array}$ & $\begin{array}{l}\text { Mean } \\
\text { follow-up }\end{array}$ \\
\hline (32) & 14 & MEN2, VHL & Open & $21 \%$ & $93 \%$ & 138 months \\
\hline (33) & 36 & MEN2, VHL & Open & $3 \%$ & $\begin{array}{l}100 \% \text { (subnormal } \\
\text { response to ACTH test } \\
\text { in } 20 \% \text {, not requiring } \\
\text { supplementation) }\end{array}$ & 73 months \\
\hline (29) & 12 & MEN2, VHL, NF1 & Open & $0 \%$ & $\begin{array}{l}100 \% \text { (subnormal } \\
\text { response to ACTH test } \\
\text { in } 50 \% \text {, not requiring } \\
\text { supplementation) }\end{array}$ & 37 months \\
\hline (53) & 26 & MEN2, VHL, NF1 & Open or laparoscopic & $10 \%$ & $65 \%$ & 71 months \\
\hline (30) & 10 & Hereditary & Open or laparoscopic & $0 \%$ & $90 \%$ & 36 months \\
\hline (27) & 13 & MEN2 & Open or laparoscopic & $\begin{array}{l}51.8 \% \\
\quad(\text { estimated })^{a}\end{array}$ & Not evaluable $^{a}$ & 120 months \\
\hline (28) & 26 & VHL & Open or laparoscopic & $11 \%$ & $89 \%$ & 111 months \\
\hline (26) & 57 & MEN2, VHL & $\begin{array}{l}\text { Retroperitoneoscopic } \\
\text { or laparoscopic }\end{array}$ & $\begin{array}{l}0 \% \text { (1 persistent } \\
\text { disease) }\end{array}$ & $91 \%$ & 48 months \\
\hline (31) & 33 & MEN2, VHL & Open or laparoscopic & $7 \%$ & $58 \%$ & 96 months \\
\hline (12) & 114 & MEN2 & Open or laparoscopic & $3 \%$ & $57 \%$ & 120 months \\
\hline
\end{tabular}

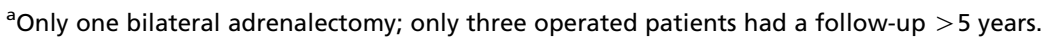


these patients. The definition of normal cortical function should be more clearly determined when there is no need for substitutive treatment or a normal response to the ACTH test. A subsequent repetition of the test may lead to a normal response to ACTH in patients with normal basal cortisol levels. The two most recent studies reported the lowest rates of normal adrenal function $(12,31)$ in primarily MEN2 patients who underwent minimally invasive surgery. These results may be observed because several smaller pheochromocytomas were detected during the surgery, and it was not possible to maintain a sufficient adrenal remnant to avoid glucocorticoid substitution. The only study that compared cortical sparing adrenal surgery with total adrenalectomy demonstrated a significant difference between groups (43\% vs $100 \%$ patients with adrenal insufficiency respectively) (12). Cortical sparing adrenal surgery is likely an effective procedure to maintain normal adrenal function (Fig. 3).

The results of cortical sparing adrenal surgery in MEN2 strongly suggest that surgeons should perform cortical sparing surgery in patients with a history of renal/adrenal trauma (with only one remaining gland) when technically feasible. We consider that cortical sparing surgery should be the preferred method in cases of MEN2- or VHL-associated unilateral pheochromocytoma because of the high risk of contralateral metachronous pheochromocytoma. Some authors suggest that the low risk of

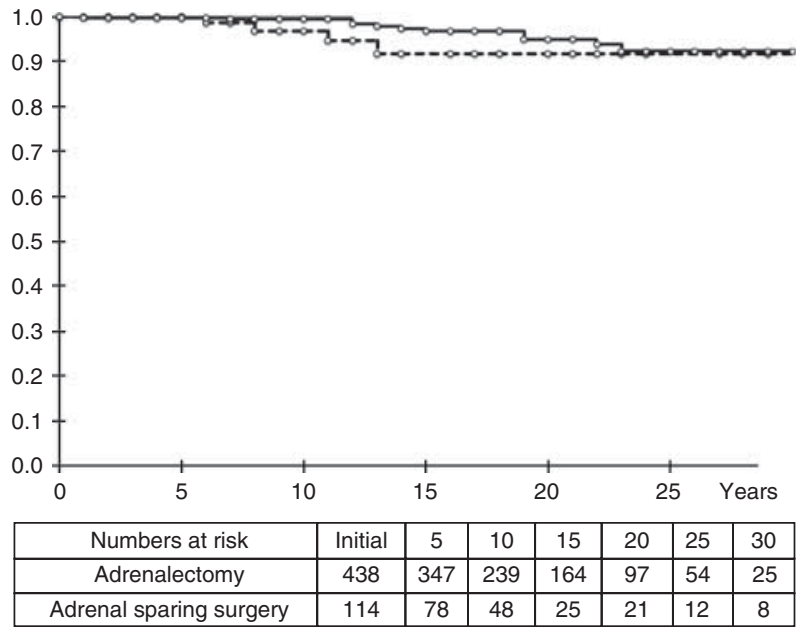

\section{Figure 3}

Disease-free survival after cortical sparing surgery and total adrenalectomy based on 563 patients carrying MEN2-associated pheochromocytoma (adapted from Castinetti et al. (12). Plain line, total adrenalectomy; dotted line, cortical sparing adrenal surgery. malignity of MEN2-associated pheochromocytoma support a waiting attitude in cases of unilateral nonsymptomatic pheochromocytoma. However, the possible occurrence of several pheochromocytoma on the contralateral gland, which complicates cortical sparing surgery, is strong evidence for the performance of partial adrenalectomy at the first diagnosis of pheochromocytoma when possible. We encourage surgeons to perform bilateral adrenal sparing surgery in patients with bilateral pheochromocytoma at diagnosis. The risk of recurrence will obviously be higher, but performing unilateral total adrenalectomy at the time of recurrence will allow patients to maintain normal cortical function via the spared contralateral gland for a prolonged period of time. It is also obvious that the second surgery will likely be more difficult in these patients, but the final aim of preserving cortical function for the longest period of time is obtained.

\section{Managing the follow-up after cortical sparing adrenal surgery}

The follow-up determines glucocorticoid function and identifies a potential recurrence. There are no guidelines for patient follow-up after bilateral adrenalectomy with at least one cortical sparing adrenal surgery to detect the need for substitutive treatments. One reasonable approach would be to treat the patients systematically with glucocorticoids (supplemental dose) after surgery and evaluate before glucocorticoid intake $0800 \mathrm{~h}$ plasma ACTH and cortisol at 1, 3, 6, and 12 months (if still less than normal) after surgery. A cortisol value $>140 \mathrm{nmol} / \mathrm{l}$ should lead to an ACTH stimulation test, which will allow the withdrawal of glucocorticoids if cortisol $>550 \mathrm{nmol} / \mathrm{l}$. This approach is similar to the guidelines for the follow-up of classical adrenal insufficiency patients (15). The probability of recovering a normal adrenal function for more than 1 year after surgery seems highly unlikely.

The symptoms and signs of catecholamine oversecretion are rarely effective markers to detect recurrence. The follow-up is identical to the follow-up for mutation carriers based on annual plasma and/or urinary metanephrines and normetanephrines assessments. A negative biology does not exclude a small pheochromocytoma, which is not a fatal event in regularly followed patients. Notably, the genotype per se does not modify the risk of recurrence, but it might shorten the period between surgery and recurrence. This result is supported by the fact that patients with germline mutations of exon 11 of the RET gene exhibit pheochromocytoma at a younger age 
than patients carrying exon 10 mutations (12). The role of systematic conventional imaging during the follow-up is controversial, and it should not be more frequent than for mutation carriers before the first diagnosis of pheochromocytoma. However, there is a larger place for high-resolution nuclear imaging in cases of positive biology because CT and MRI are less effective in detecting small local recurrence. ${ }^{18} \mathrm{~F}-\mathrm{FDOPA}$ PET/CT may provide further information to distinguish between compensatory adrenal cortex remnant hyperplasia and recurrent pheochromocytoma. Obviously, the follow-up is also aimed at the detection of contralateral pheochromocytoma in cases of unilateral adrenalectomy. Management of recurrence is currently based on total adrenalectomy, but one study reported the possibility of performing another partial procedure, similar to the multi-surgical management of hyperparathyroidism in multiple endocrine neoplasia ${ }^{44}$.

\section{Conclusions and future directions}

Pheochromocytoma patients need highly individualized interdisciplinary evaluation and treatment.

Cortical sparing endoscopic surgery is a safe and effective procedure for the management of hereditary bilateral pheochromocytoma in referral centers. In this context, the knowledge of genetic status before surgery may be useful (phenotypically for VHL, using calcitonin measurement for MEN2, and genetically for SDHB) to create a tailored optimal management strategy. The 10 -year risk of recurrence is low, and more than $50 \%$ of patients will maintain normal glucocorticoid function for 10 years. However, this approach is not systematically proposed. Only 33\% of the patients in our international study were treated using cortical sparing adrenal surgery between 2009 and 2014 (12). This low frequency should be considered an anomaly because this approach can alter the functional outcome of primarily young patients for a prolonged period of time. Cortical sparing adrenal surgery should now be considered the preferred method, even at the first diagnosis of metachronous pheochromocytoma, and these data emphasize the need for optimal management in expert centers.

Further studies should determine the long-term risk of recurrence after cortical sparing adrenal surgery because this rate likely dramatically increases after 10 years of follow-up. Finally, future studies should also help determine whether cortical sparing adrenal surgery should be proposed to patients with sporadic unilateral pheochromocytoma. Cortical sparing adrenal surgery may be a valuable option because of the monoclonal nature of sporadic unilateral pheochromocytoma and the lack of hyperplasia that surrounds the tissue. This technique was successfully performed in aldosterone-producing adenoma (57), and this technique is already an option in patients with unilateral pheochromocytoma and loss of the contralateral adrenal gland due to previous surgery or trauma. Optimal management performed by experts in cortical sparing surgery may also aid in the repeating of partial adrenalectomy in case of recurrence to delay the development of adrenal insufficient.

Declaration of interest

The authors declare that there is no conflict of interest that could be perceived as prejudicing the impartiality of the review.

\section{Funding}

This research did not receive any specific grant from any funding agency in the public, commercial or not-for-profit sector.

\section{Acknowledgements}

The authors would like to thank the following clinicians who took part in the previously published study on cortical sparing surgery: M K Alevizaki (Athens, Greece), M Barczynski (Krakow, Poland), M Barontini (Buenos Aires, Argentina), B Bausch (Freiburg, Germany), S R Bergmann (Marburg, Germany), J Biarnes Costa (Girona, Spain), M Brauckhoff (Bergen, Norway), M J Bugalho (Lisbon, Portugal), L Canu (Florence, Italy), F L Coutinho (Sao Paulo, Brazil), T Cuny (Nancy, France), M Czetwertynska (Warsaw, Poland), L Demarquet (Nancy, France), S Dvorakova (Prague, Czech Republic), C Eng (Cleveland, OH, USA), K Hasse-Lazar (Gliwice, Poland), A Januszewicz (Warsaw, Poland), B Jarzab (Gliwice, Poland), O Kollyukh (Kiev, Ukraine), C Letizia (Rome, Italy), T P Links (Groningen, Netherlands), P Loli (Milan, Italy), A L Maia (Porto Alegre, Brazil), O Makay (Izmir, Turkey), M Mannelli (Florence, Italy), C Mian (Padova, Italy), G Opocher (Padova, Italy), A Patocs (Budapest, Hungary), M Peczkowska (Warsaw, Poland), L Petramala (Rome, Italy), M Pfeifer (Ljubljana, Slovenia), J T Plukker (Groningen, Netherlands), X P Qi (Hangzhou, China), K Racz (Budapest, Hungary), $M$ Recasens (Girona, Spain), G Sansó (Buenos Aires, Argentina), P Sartorato (Treviso, Italy), F Schiavi (Padova, Italy), N S Shah (Mumbai, India), D R Siqueira (Porto Alegre, Brazil), M Szperl (Warsaw, Poland), R A Toledo (Sao Paulo, Brazil), S P Toledo (Sao Paulo, Brazil), M U Ugurlu (Istanbul, Turkey), G Valk (Utrecht, Netherlands), H H Verbeek (Groningen, Netherlands), P Vlcek (Prague, Czech Republic), E Von Dobschuetz (Freiburg, Germany), G Weryha (Nancy, France), N Wohllk (Santiago de Chile, Chile), S Yaremchuk (Kiev, Ukraine), D Zabolotnyi (Kiev, Ukraine), and T Zelinka (Prague, Czech Republic).

\section{References}

1 Lenders JW, Eisenhofer G, Mannelli M \& Pacak K. Phaeochromocytoma. Lancet 2005366 665-675. (doi:10.1016/S0140-6736(05)67139-5)

2 Lenders JW, Duh QY, Eisenhofer G, Gimenez-Roqueplo AP, Grebe SK, Murad MH, Naruse M, Pacak K \& Young WF Jr. Pheochromocytoma and paraganglioma: an endocrine society clinical practice guideline. Journal of Clinical Endocrinology and Metabolism 201499 1915-1942. (doi:10.1210/jc.2014-1498) 
3 Gimenez-Roqueplo AP, Dahia PL \& Robledo M. An update on the genetics of paraganglioma, pheochromocytoma, and associated hereditary syndromes. Hormone and Metabolic Research $2012 \mathbf{4 4}$ 328-333. (doi:10.1055/s-0031-1301302)

4 Amar L, Bertherat J, Baudin E, Ajzenberg C, Bressac-de Paillerets B, Chabre O, Chamontin B, Delemer B, Giraud S, Murat A et al. Genetic testing in pheochromocytoma or functional paraganglioma. Journal of Clinical Oncology 200523 8812-8818. (doi:10.1200/JCO.2005.03.1484)

5 Mannelli M, Castellano M, Schiavi F, Filetti S, Giacche M, Mori L, Pignataro V, Bernini G, Giache V, Bacca A et al. Clinically guided genetic screening in a large cohort of italian patients with pheochromocytomas and/or functional or nonfunctional paragangliomas. Journal of Clinical Endocrinology and Metabolism 200994 1541-1547. (doi:10.1210/jc.2008-2419)

6 Dahia PL. Pheochromocytoma and paraganglioma pathogenesis: learning from genetic heterogeneity. Nature Reviews. Cancer 201414 108-119. (doi:10.1038/nrc3648)

7 Favier J, Amar L \& Gimenez-Roqueplo AP. Paraganglioma and phaeochromocytoma: from genetics to personalized medicine. Nature Reviews. Endocrinology 201511 101-111. (doi:10.1038/nrendo.2014.188)

8 Wells SA Jr, Pacini F, Robinson BG \& Santoro M. Multiple endocrine neoplasia type 2 and familial medullary thyroid carcinoma: an update. Journal of Clinical Endocrinology and Metabolism 201398 3149-3164. (doi:10.1210/jc.2013-1204)

9 Schmid S, Gillessen S, Binet I, Brandle M, Engeler D, Greiner J, Hader C, Heinimann K, Kloos P, Krek W et al. Management of von hippel-lindau disease: an interdisciplinary review. Oncology Research and Treatment 201437 761-771. (doi:10.1159/000369362)

10 Wells SA Jr, Asa SL, Dralle H, Elisei R, Evans DB, Gagel RF, Lee NY, Machens A, Moley JF, Pacini F et al. Revised American Thyroid Association Guidelines for the Management of Medullary Thyroid Carcinoma The American Thyroid Association Guidelines Task Force on Medullary Thyroid Carcinoma. Thyroid 201525 567-610. (doi:10.1089/thy.2014.0335)

11 Thosani S, Ayala-Ramirez M, Palmer L, Hu MI, Rich T, Gagel RF, Cote G, Waguespack SG, Habra MA \& Jimenez C. The characterization of pheochromocytoma and its impact on overall survival in multiple endocrine neoplasia type 2. Journal of Clinical Endocrinology and Metabolism 201398 E1813-E1819. (doi:10.1210/jc.2013-1653)

12 Castinetti F, Qi XP, Walz MK, Maia AL, Sanso G, Peczkowska M, HasseLazar K, Links TP, Dvorakova S, Toledo RA et al. Outcomes of adrenalsparing surgery or total adrenalectomy in phaeochromocytoma associated with multiple endocrine neoplasia type 2: an international retrospective population-based study. Lancet. Oncology 201415 648-655. (doi:10.1016/S1470-2045(14)70154-8)

13 JAMA Editorial. Bilateral adrenalectomy for Cushing's syndrome. Journal of the American Medical Association 1953153 567. (doi:10.1001/ jama.1953.02940230039009)

14 Lairmore TC, Ball DW, Baylin SB \& Wells SA Jr. Management of pheochromocytomas in patients with multiple endocrine neoplasia type 2 syndromes. Annals of Surgery 1993217 595-601; discussion 601-593. (doi:10.1097/00000658-199306000-00001)

15 Husebye ES, Allolio B, Arlt W, Badenhoop K, Bensing S, Betterle C, Falorni A, Gan EH, Hulting AL, Kasperlik-Zaluska A et al. Consensus statement on the diagnosis, treatment and follow-up of patients with primary adrenal insufficiency. Journal of Internal Medicine 2014275 104-115. (doi:10.1111/joim.12162)

16 Hahner S, Hemmelmann N, Quinkler M, Beuschlein F, Spinnler C \& Allolio B. Timelines in the management of adrenal crisis - targets, limits and reality. Clinical Endocrinology 201582 497-502. (doi:10.1111/cen. 12609)

17 Hahner S, Spinnler C, Fassnacht M, Burger-Stritt S, Lang K, Milovanovic D, Beuschlein F, Willenberg HS, Quinkler M \& Allolio B. High incidence of adrenal crisis in educated patients with chronic adrenal insufficiency: a prospective study. Journal of
Clinical Endocrinology and Metabolism 2015100 407-416. (doi:10.1210/ jc.2014-3191)

18 Inabnet WB, Caragliano P \& Pertsemlidis D. Pheochromocytoma: inherited associations, bilaterality, and cortex preservation. Surgery 2000128 1007-1011; discussion 1011-1002. (doi:10.1067/msy.2000. 110846)

19 Eisenhofer G, Pacak K, Huynh TT, Qin N, Bratslavsky G, Linehan WM, Mannelli M, Friberg P, Grebe SK, Timmers HJ et al. Catecholamine metabolomic and secretory phenotypes in phaeochromocytoma. Endocrine-Related Cancer 201118 97-111. (doi:10.1677/ERC-10-0211)

20 Taieb D, Kebebew E, Castinetti F, Chen CC, Henry JF \& Pacak K. Diagnosis and preoperative imaging of multiple endocrine neoplasia type 2: current status and future directions. Clinical Endocrinology 2014 81 317-328. (doi:10.1111/cen.12513)

21 Luster M, Karges W, Zeich K, Pauls S, Verburg FA, Dralle H, Glatting G, Buck AK, Solbach C, Neumaier B et al. Clinical value of 18Ffluorodihydroxyphenylalanine positron emission tomography/ computed tomography (18F-DOPA PET/CT) for detecting pheochromocytoma. European Journal of Nuclear Medicine and Molecular Imaging 201037 484-493. (doi:10.1007/s00259-009-1294-7)

22 Taieb D, Timmers HJ, Hindie E, Guillet BA, Neumann HP, Walz MK, Opocher G, de Herder WW, Boedeker CC, de Krijger RR et al. EANM guidelines for radionuclide imaging of phaeochromocytoma and paraganglioma. European Journal of Nuclear Medicine and Molecular Imaging 201239 1977-1995. (doi:10.1007/s00259-012-2215-8)

23 Castinetti F, Kroiss A, Kumar R, Pacak K \& Taieb D. Imaging and imaging-based treatment of pheochromocytoma and paraganglioma. Endocrine-Related Cancer 201522 T135-T145. (doi:10.1530/ERC15-0175)

24 Timmers HJ, Kozupa A, Chen CC, Carrasquillo JA, Ling A, Eisenhofer G, Adams KT, Solis D, Lenders JW \& Pacak K. Superiority of fluorodeoxyglucose positron emission tomography to other functional imaging techniques in the evaluation of metastatic SDHB-associated pheochromocytoma and paraganglioma. Journal of Clinical Oncology 200725 2262-2269. (doi:10.1200/JCO.2006.09.6297)

25 Jafri M \& Maher ER. The genetics of phaeochromocytoma: using clinical features to guide genetic testing. European Journal of Endocrinology 2012166 151-158. (doi:10.1530/EJE-11-0497)

26 Alesina PF, Hinrichs J, Meier B, Schmid KW, Neumann HP \& Walz MK. Minimally invasive cortical-sparing surgery for bilateral pheochromocytomas. Langenbeck's Archives of Surgery 2012397 233-238. (doi:10.1007/s00423-011-0851-2)

27 Asari R, Scheuba C, Kaczirek K \& Niederle B. Estimated risk of pheochromocytoma recurrence after adrenal-sparing surgery in patients with multiple endocrine neoplasia type 2A. Archives of Surgery 2006141 1199-1205; discussion 1205. (doi:10.1001/archsurg. 141.12.1199)

28 Benhammou JN, Boris RS, Pacak K, Pinto PA, Linehan WM \& Bratslavsky G. Functional and oncologic outcomes of partial adrenalectomy for pheochromocytoma in patients with von Hippel-Lindau syndrome after at least 5 years of followup. Journal of Urology $2010 \mathbf{1 8 4}$ 1855-1859. (doi:10.1016/j.juro.2010.06.102)

29 Brauckhoff M, Gimm O, Thanh PN, Bar A, Ukkat J, Brauckhoff K, Bonsch T \& Dralle H. Critical size of residual adrenal tissue and recovery from impaired early postoperative adrenocortical function after subtotal bilateral adrenalectomy. Surgery 2003134 1020-1027; discussion 1027-1028. (doi:10.1016/j.surg.2003.08.005)

30 Diner EK, Franks ME, Behari A, Linehan WM \& Walther MM. Partial adrenalectomy: the National Cancer Institute experience. Urology 2005 66 19-23. (doi:10.1016/j.urology.2005.01.009)

31 Grubbs EG, Rich TA, Ng C, Bhosale PR, Jimenez C, Evans DB, Lee JE \& Perrier ND. Long-term outcomes of surgical treatment for hereditary pheochromocytoma. Journal of the American College of Surgeons 2013 216 280-289. (doi:10.1016/j.jamcollsurg.2012.10.012) 
32 Lee JE, Curley SA, Gagel RF, Evans DB \& Hickey RC. Cortical-sparing adrenalectomy for patients with bilateral pheochromocytoma. Surgery 1996120 1064-1070; discussion 1070-1061. (doi:10.1016/S00396060(96)80056-0)

33 Neumann HP, Bender BU, Reincke M, Eggstein S, Laubenberger J \& Kirste G. Adrenal-sparing surgery for phaeochromocytoma. British Journal of Surgery 199986 94-97. (doi:10.1046/j.1365-2168.1999.00974.x)

34 Walz MK, Peitgen K, Saller B, Giebler RM, Lederbogen S, Nimtz K, Mann K \& Eigler FW. Subtotal adrenalectomy by the posterior retroperitoneoscopic approach. World Journal of Surgery 199822 621-626; discussion 626-627. (doi:10.1007/s002689900444)

35 Korpershoek E, Petri BJ, Post E, van Eijck CH, Oldenburg RA, Belt EJ, de Herder WW, de Krijger RR \& Dinjens WN. Adrenal medullary hyperplasia is a precursor lesion for pheochromocytoma in MEN2 syndrome. Neoplasia 201416 868-873. (doi:10.1016/j.neo.2014.09. 002)

36 Scholten A, Vriens MR, Cromheecke GJ, Borel Rinkes IH \& Valk GD. Hemodynamic instability during resection of pheochromocytoma in MEN versus non-MEN patients. European Journal of Endocrinology 2011 165 91-96. (doi:10.1530/EJE-11-0148)

37 Lafont M, Fagour C, Haissaguerre M, Darancette G, Wagner T, Corcuff JB \& Tabarin A. Per-operative hemodynamic instability in normotensive patients with incidentally discovered pheochromocytomas. Journal of Clinical Endocrinology and Metabolism 2015100 417-421. (doi:10.1210/jc.2014-2998)

38 van Heerden JA, Sheps SG, Hamberger B, Sheedy PF II, Poston JG \& ReMine WH. Pheochromocytoma: current status and changing trends. Surgery 198291 367-373.

39 Orchard T, Grant CS, van Heerden JA \& Weaver A. Pheochromocytoma-continuing evolution of surgical therapy. Surgery $1993 \mathbf{1 1 4}$ 1153-1158; discussion 1158-1159.

40 Gagner M, Lacroix A \& Bolte E. Laparoscopic adrenalectomy in Cushing's syndrome and pheochromocytoma. New England Journal of Medicine 1992327 1033. (doi:10.1056/NEJM199210013271417)

41 Gill IS. The case for laparoscopic adrenalectomy. Journal of Urology 2001 166 429-436. (doi:10.1016/S0022-5347(05)65958-7)

42 Zacharias M, Haese A, Jurczok A, Stolzenburg JU \& Fornara P. Transperitoneal laparoscopic adrenalectomy: outline of the preoperative management, surgical approach, and outcome. European Urology 200649 448-459. (doi:10.1016/j.eururo.2006.01.014)

43 Nambirajan T, Bagheri F, Abdelmaksoud A, Leeb K, Neumann H, Graubner UB \& Janetschek G. Laparoscopic partial adrenalectomy for recurrent pheochromocytoma in a boy with Von Hippel-Lindau disease. Journal of Laparoendoscopic \& Advanced Surgical Techniques. Part A 200414 234-235. (doi:10.1089/lap.2004.14.234)

44 Brauckhoff M, Gimm O, Brauckhoff K \& Dralle H. Repeat adrenocortical-sparing adrenalectomy for recurrent hereditary pheochromocytoma. Surgery Today 200434 251-255. (doi:10.1007/ s00595-003-2690-4)

45 Walz MK, Peitgen K, Hoermann R, Giebler RM, Mann K \& Eigler FW. Posterior retroperitoneoscopy as a new minimally invasive approach for adrenalectomy: results of 30 adrenalectomies in 27 patients. World Journal of Surgery 199620 769-774. (doi:10.1007/s002689900117)

46 Lee CR, Walz MK, Park S, Park JH, Jeong JS, Lee SH, Kang SW, Jeong JJ, Nam KH, Chung WY et al. A comparative study of the transperitoneal and posterior retroperitoneal approaches for laparoscopic adrenalectomy for adrenal tumors. Annals of Surgical Oncology 201219 2629-2634. (doi:10.1245/s10434-012-2352-0)

47 Giebler RM, Walz MK, Peitgen K \& Scherer RU. Hemodynamic changes after retroperitoneal CO2 insufflation for posterior retroperitoneoscopic adrenalectomy. Anesthesia and Analgesia 199682 827-831.

48 Suzuki K. Laparoscopic adrenalectomy: retroperitoneal approach. Urologic Clinics of North America 200128 85-95. (doi:10.1016/S00940143(01)80010-0)

49 Mazzaglia PJ \& Vezeridis MP. Laparoscopic adrenalectomy: balancing the operative indications with the technical advances. Journal of Surgical Oncology 2010101 739-744. (doi:10.1002/jso.21565)

50 Barczynski M, Konturek A \& Nowak W. Randomized clinical trial of posterior retroperitoneoscopic adrenalectomy versus lateral transperitoneal laparoscopic adrenalectomy with a 5-year follow-up. Annals of Surgery 2014260 740-747; discussion 747-748. (doi:10.1097/SLA. 0000000000000982)

51 Cabalag MS, Mann GB, Gorelik A \& Miller JA. Comparison of outcomes after laparoscopic versus posterior retroperitoneoscopic adrenalectomy: a pilot study. Surgical Laparoscopy, Endoscopy \& Percutaneous Techniques 201424 62-66. (doi:10.1097/SLE.0b013e31828fa71f)

52 Walz MK, Peitgen K, Diesing D, Petersenn S, Janssen OE, Philipp T, Metz KA, Mann K, Schmid KW \& Neumann HP. Partial versus total adrenalectomy by the posterior retroperitoneoscopic approach: early and long-term results of 325 consecutive procedures in primary adrenal neoplasias. World Journal of Surgery 200428 1323-1329. (doi:10.1007/s00268-004-7667-y)

53 Yip L, Lee JE, Shapiro SE, Waguespack SG, Sherman SI, Hoff AO, Gagel RF, Arens JF \& Evans DB. Surgical management of hereditary pheochromocytoma. Journal of the American College of Surgeons 2004 198 525-534; discussion 534-525. (doi:10.1016/j.jamcollsurg.2003.12. 001)

54 Walz MK, Peitgen K, Neumann HP, Janssen OE, Philipp T \& Mann K. Endoscopic treatment of solitary, bilateral, multiple, and recurrent pheochromocytomas and paragangliomas. World Journal of Surgery 200226 1005-1012. (doi:10.1007/s00268-002-6632-x)

55 Gagner M, Breton G, Pharand D \& Pomp A. Is laparoscopic adrenalectomy indicated for pheochromocytomas? Surgery 1996 120 1076-1079; discussion 1079-1080. (doi:10.1016/S00396060(96)80058-4)

56 Brunt LM, Lairmore TC, Doherty GM, Quasebarth MA, DeBenedetti M $\&$ Moley JF. Adrenalectomy for familial pheochromocytoma in the laparoscopic era. Annals of Surgery 2002235 713-720; discussion 720-711. (doi:10.1097/00000658-200205000-00014)

57 Kok KY \& Yapp SK. Laparoscopic adrenal-sparing surgery for primary hyperaldosteronism due to aldosterone-producing adenoma. Surgical Endoscopy 200216 108-111. (doi:10.1007/s00464-001-8127-5)

Received 4 June 2015

Revised version received 20 August 2015

Accepted 21 August 2015 